\title{
Development and Performance Evaluation of a Porous Tube Dilutor for Real-time Measurements of Fine Particles in High-humidity Environments
}

\author{
Chang Gyu Woo ${ }^{1}$, Ki-Jung Hong ${ }^{1}$, Hak-Joon Kim ${ }^{1}$, Yong-Jin Kim ${ }^{1}$, Bangwoo Han ${ }^{1 *}$, \\ Jeongeun $\mathrm{An}^{2}$, Su Ji Kang ${ }^{3}$, Sung-Nam Chun ${ }^{3}$ \\ ${ }^{1}$ Department of Environmental Machinery, Korea Institute of Machinery \& Materials, Daejeon 34103, Korea \\ ${ }^{2}$ Parkor Korea Indus Co., Ltd., Seoul 08584, Korea \\ ${ }^{3}$ Clean Power Generation Laboratory, KEPCO Research Institute, Daejeon 34056, Korea
}

\begin{abstract}
Real-time measurement of fine particles in stack emission gases is an important component in continuous environmental monitoring of $\mathrm{PM}_{10}$ and $\mathrm{PM}_{2.5}$. We developed a porous tube dilutor (using both hot and cold dilution) to measure fine, but not condensable, particles in highly humid gas emissions and compared our device to a commercial ejector-type dilutor. Particle size distributions were measured in emissions from a diesel engine and a coal-fired boiler. The porous tube dilutor successfully measured particles in accumulation mode, including relatively large particles over $3 \mu \mathrm{m}$ in diameter (without nuclei), whereas the ejector dilutor detected some condensable particles but could not detect large particles. The porous tube dilutor successfully removed condensed water droplets generated by a humidifier in a $30-\mathrm{m}^{3}$ chamber.
\end{abstract}

Keywords: Sampling; $\mathrm{PM}_{10} ; \mathrm{PM}_{2.5}$; Dilution; Condensable.

\section{INTRODUCTION}

Health concerns arise on days with high $\mathrm{PM}_{10}$ or $\mathrm{PM}_{2.5}$ levels (Health Effects Institute, 2017). To reduce $\mathrm{PM}_{10}$ or $\mathrm{PM}_{2.5}$ levels, precise measurements at the source of $\mathrm{PM}_{10}$ and $\mathrm{PM}_{2.5}$ are required so that the causes of generation can be analyzed and appropriate reduction technologies applied. Currently, fine particle measurements at fixed sources are performed manually via sampling and mass measuring; this takes at least 2-3 days and, potentially, over a week (Environmental Protection Agency, 1998). Thus, it is difficult to analyze fine particle emission status and control the concentrations thereof in real time.

Most environments emitting fine particles are highly humid. When particles are measured using existing realtime instruments, it is impossible to precisely measure fine particles because of the presence of condensable particles

\footnotetext{
* Corresponding author.

Tel.: 82-42-868-7068; Fax: 82-42-868-7284

E-mail address: bhan@kimm.re.kr
}

This article is an English version of "Development and Performance Evaluation of the Porous Tube Dilutor for Real-time Measurements of Fine Particles from High Humidity Environments" published in the Particle and Aerosol Research in September 2017. generated during the sampling process (Lipsky et al., 2005). When measuring car emissions, a hot dilution method is used to suppress the generation of condensable particles (hot air is injected). Ejector and rotating disk dilutors using hot-dilution methods are commercially available (Lyyränen et al., 2004; Burtscher, 2005; Li et al., 2011) (Fig. 1). However, particle loss, caused by air-mixing and cavity transport, occurs during dilution; it is difficult to precisely measure $\mathrm{PM}_{10}$ or $\mathrm{PM}_{2.5}$ levels (Lipsky et al., 2002).

In this study, we developed a sampler with a porous tube dilutor (Deuerling et al., 2010) exhibiting low-level particle loss, and suppressed condensable particle generation. We compared our dilutor with a commercial ejector-type dilutor (DEED; Dekati Ltd., Kangasala, Finland) in terms of measurement of particles emitted by a car diesel engine and a coal-fired boiler. Condensable particle suppression and the extent of large particle loss were compared. Condensable particle reduction characteristics were compared using a test chamber featuring high-level humidity.

\section{METHODS}

Fig. 2 shows the porous tube dilutor. The first-dilution air (heated to $200^{\circ} \mathrm{C}$ ) was introduced via a high-velocity ejector nozzle. The negative pressure created by the airflow allowed air containing fine particles to enter the sampling probe. The second-dilution air, at ambient temperature, was injected into the end of the ejector through a metallic, porous cylindrical tube filled with 20 - $\mu$ m-diameter beads. 


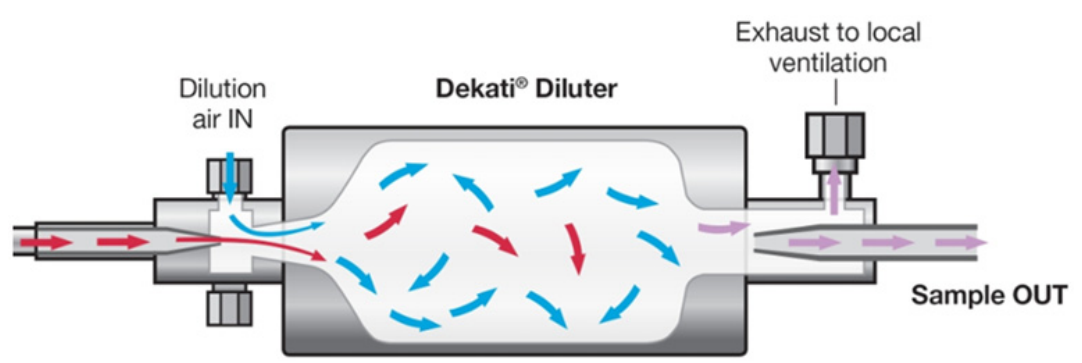

(a)

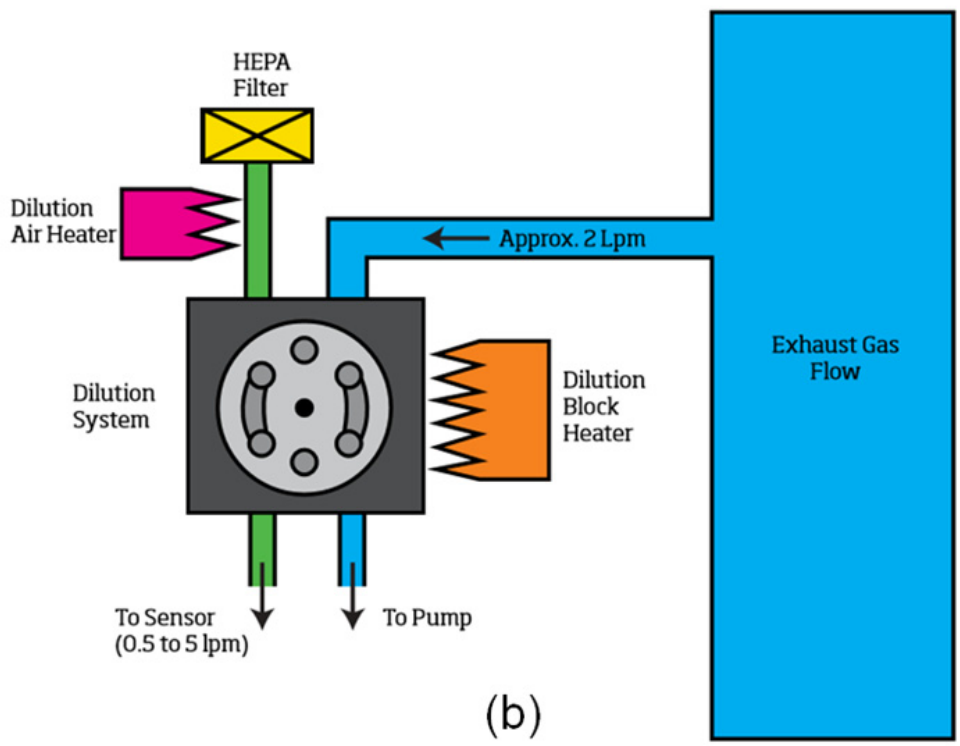

Fig. 1. Commercial dilutors: (a) an ejector dilutor (Dekati ${ }^{\circledR}$ Dilutor) and (b) a rotating disk dilutor (MD19-2E; Matter Engineering, Kirchberg, Switzerland).

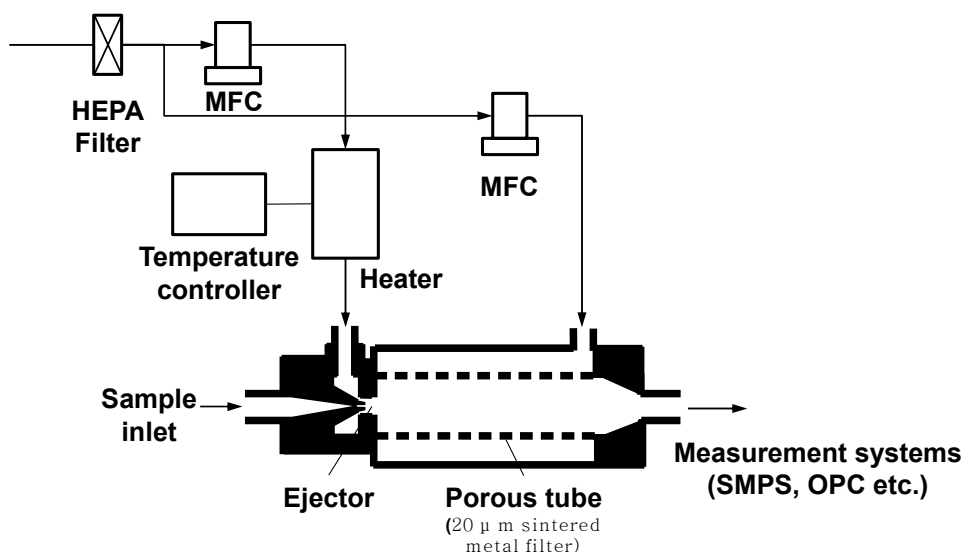

Fig. 2. The porous tube dilutor used in this work.

Particle loss at the inner wall during mixing at the end of the ejector was minimized by the porous structure.

First, to measure fine particles in diesel exhaust gas of high humidity and high temperature, a diesel engine was connected to a dynamo system. The displacement of the commercial car engine used (Santa Fé; Hyundai Motor Company, Seoul, Korea) was 1,991 $\mathrm{mL}$, and the maximum output was 126 PS $(92.7 \mathrm{~kW})$ at $4,000 \mathrm{rpm}$. The engine oil employed was SAE 10W/30 (Hyundai Mobis, Seoul, Korea).
Most experiments were performed at 2,000 rpm, with a torque of $18 \mathrm{~kg} \mathrm{~m}^{-1}$ and an exhaust gas temperature of $530^{\circ} \mathrm{C}$. Using the DEED and our new diluting sampler, exhaust gas was sampled before passage through the diesel particulate filter (DPF) and analyzed using the particle analyzer of the Scanning Mobility Particle Sizer (SMPS + C; Grimm Aerosol Technik Ainring GmbH \& Co. KG, Ainring, Germany). The dilution ratios were fixed at 100 for the DEED and 10-20 for our new diluting sampler. 
Fine particles were prepared using a $100,000 \mathrm{kcal} \mathrm{h}^{-1}$ coal-fired boiler (GV-10; Global Village Grand Vision Co., Ltd, Siheung-Si, Korea). The coal, Vietnamese anthracite, was supplied to the boiler at $20 \mathrm{~kg} \mathrm{~h}^{-1}$. The temperature of hot water from the boiler was $70^{\circ} \mathrm{C}$ and that of the exhaust gas was $100-150^{\circ} \mathrm{C}$ during testing. The size distributions of fine particles from the coal boiler were measured (0.01$10 \mu \mathrm{m})$ using the SMPS $+\mathrm{C}$ device and an Optical Particle Counter (OPC) (PAS 1.109; Grimm Aerosol Technik Ainring $\mathrm{GmbH} \&$ Co. KG, Ainring, Germany). We compared the DEED and our new dilutor.

When removing condensable particles from highly humid environments during dilution, changes in the levels of particles created by a humidifier (AOS-2055; Air-O-Swiss, Widnau, Switzerland) and an air purifier (FU-550; Sharp, Osaka, Japan) in a $30-\mathrm{m}^{3}$ test chamber $(4.0 \times 3.1 \times 2.4 \mathrm{~m})$ were measured using our dilutor. Test particles were prepared by atomizing $\mathrm{KCl}(1 \% \mathrm{w} / \mathrm{v})$ solution using an atomizer (3076; TSI Inc., Shoreview, Minnesota, USA) combined with an aerosol neutralizer (3012; TSI Inc., Shoreview, Minnesota, USA) and diffusion drier; the humidifier was used to generate condensable particles. The air purifier was employed to control $\mathrm{KCl}$ particle concentration. Changes in particle levels were measured by the OPC; the 0.25 - and $0.35-\mu \mathrm{m}$ channel particles were averaged to yield the levels of $0.3-\mu \mathrm{m}$ particles per minute.

\section{RESULTS AND DISCUSSION}

\section{Measurements of Fine Particles in Diesel Engine and Coal-fired Boiler Exhaust}

Fig. 3 shows the particle size distributions of diesel engine exhaust flowing through our dilutor at different first-dilution airflow rates. The temperature of the firstdilution air was $200^{\circ} \mathrm{C}$ and the flow rate of ambient-dilution (second-dilution) air was $37 \mathrm{~L} \mathrm{~min}^{-1}$. At $20 \mathrm{~L} \mathrm{~min}^{-1}$ of first-dilution air, peaks at 12 and $70 \mathrm{~nm}$ were evident. These were, respectively, the nuclei mode formed by saturation of condensable components (water or soluble organics), and the accumulation mode from particle accumulation. The particle numbers decreased slightly when the flow rates of first-dilution air increased from 20 to 22 and $24 \mathrm{~L} \mathrm{~min}^{-1}$. However, the condensable nucleus decreased. When the first-dilution airflow rate exceeded $26 \mathrm{~L} \mathrm{~min}^{-1}$, that nucleus disappeared but the particles associated with the $70-\mathrm{nm}$ peak remained. The dilution air was of high temperature and low relative humidity. As the flow rate of the dilution air increased, condensable nucleation was suppressed; the particle numbers in the nucleus decreased. Thus, when sufficient hot air was supplied to the porous tube dilutor, particulate matter could be reliably measured in the absence of condensable particles.

Fig. 4 shows the particle size distributions in diesel engine exhaust as measured by both the DEED and our new dilutor. The temperature of the first-dilution air for the DEED was $100^{\circ} \mathrm{C}$. The nuclei mode particles were prominent when the dilution air temperature was too low. The size distribution of particles was similar to that of our porous tube dilutor, but the level was only 0.1 -fold that of our new dilutor. Therefore, our dilutor suppressed condensable particle generation via a lower dilution airflow rate.

Fig. 5 shows the particle size distributions in coal-fired boiler exhaust using the DEED and our new dilutor. The particle concentration was normalized to the total particle number to exclude the effect of different dilution ratios. The size distributions of accumulated particles were nearlyidentical using the two kinds of dilutors. However, a condensable nucleus at about $0.01 \mu \mathrm{m}$ was evident, and fine particles over $3 \mu \mathrm{m}$ were absent, when the DEED was used. Thus, particles 3-10 $\mu \mathrm{m}$ in diameter were not measured

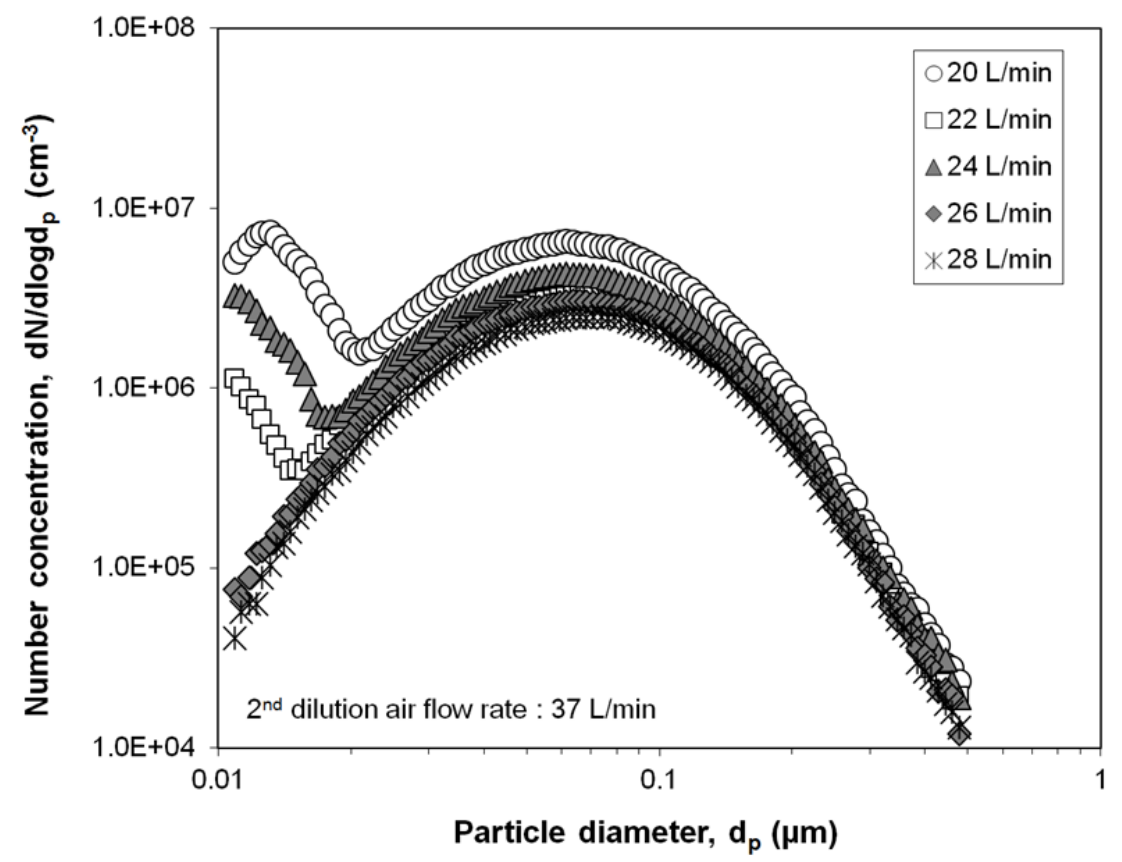

Fig. 3. The size distributions of diesel particles at different first-dilution airflow rates at $200^{\circ} \mathrm{C}$. 


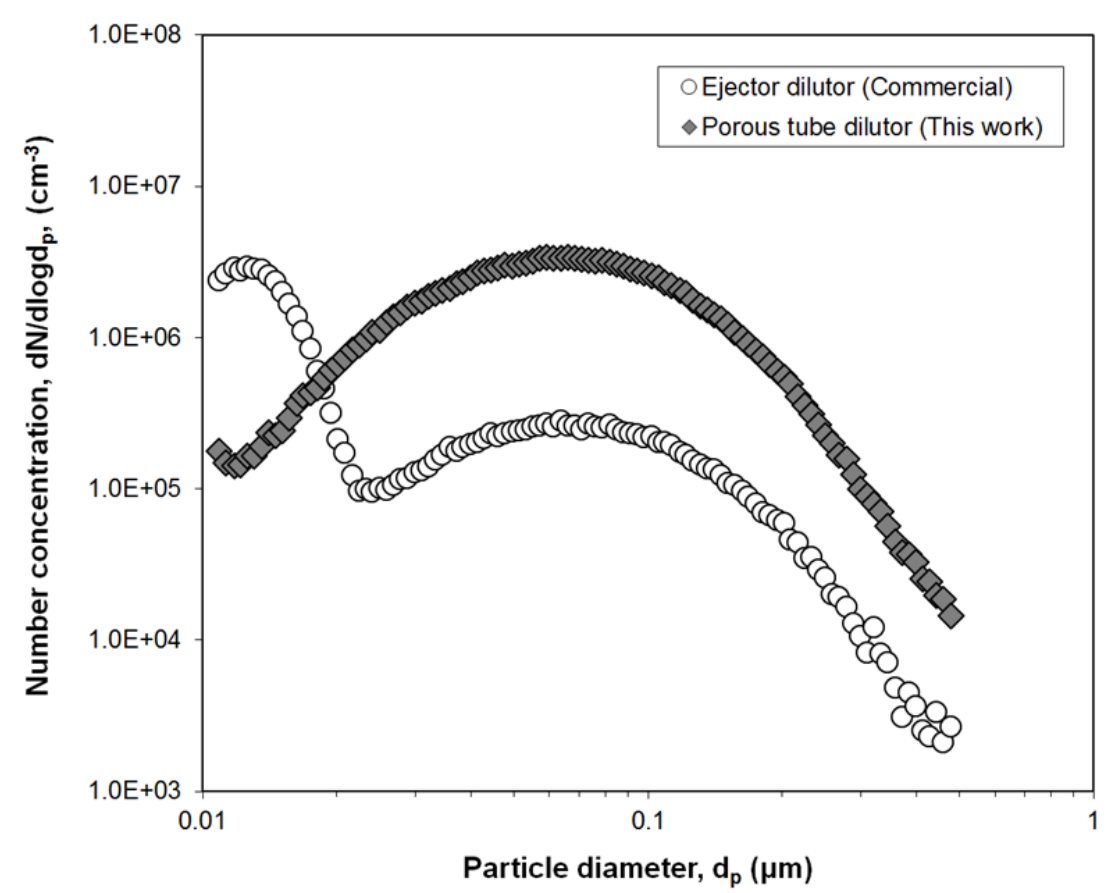

Fig. 4. The size distributions of diesel particles diluted by the ejector and porous tube dilutors.

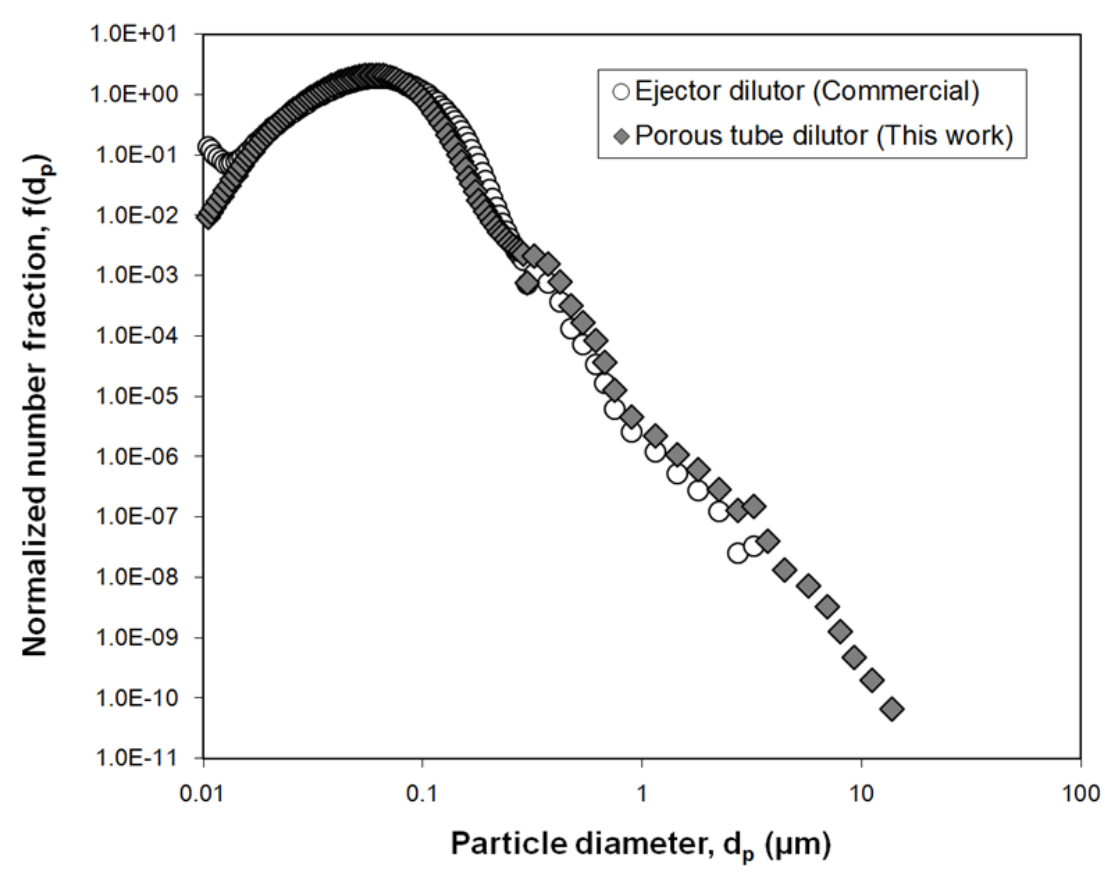

Fig. 5. The size distributions of particles from a coal-fired boiler diluted using the ejector and porous tube dilutors.

by the DEED, but were measured by our dilutor. Thus, our dilutor affords a low dilution ratio, no condensable particles, and minimal loss of large particles during mixing at the ejector.

\section{Measurement of Fine Particles in the Test Chamber}

Fig. 6 shows changes in the levels of particles between 0.25 and $0.35 \mu \mathrm{m}$ in diameter, as revealed by the OPC when $\mathrm{KCl}$ test particles were supplied to the test chamber by the atomizer when the humidifier was on. When the background concentration had attained a steady-state of 2-3 particles $\mathrm{cm}^{-3}$ for $10 \mathrm{~min}, \mathrm{KCl}$ particles were injected into the chamber over $10 \mathrm{~min}$ to 660 particles $\mathrm{cm}^{-3}$, and the concentration was then held constant for the next $10 \mathrm{~min}$. When the humidifier was switched on, the levels of $0.3-\mu \mathrm{m}$-diameter particles increased slowly for $12 \mathrm{~min}$, and then rapidly. Finally, the concentration attained 1,170 particles $\mathrm{cm}^{-3}$. In other words, the OPC could not distinguish water particles from test particles.

Fig. 7 shows particle measurements in the $30-\mathrm{m}^{3}$ test 


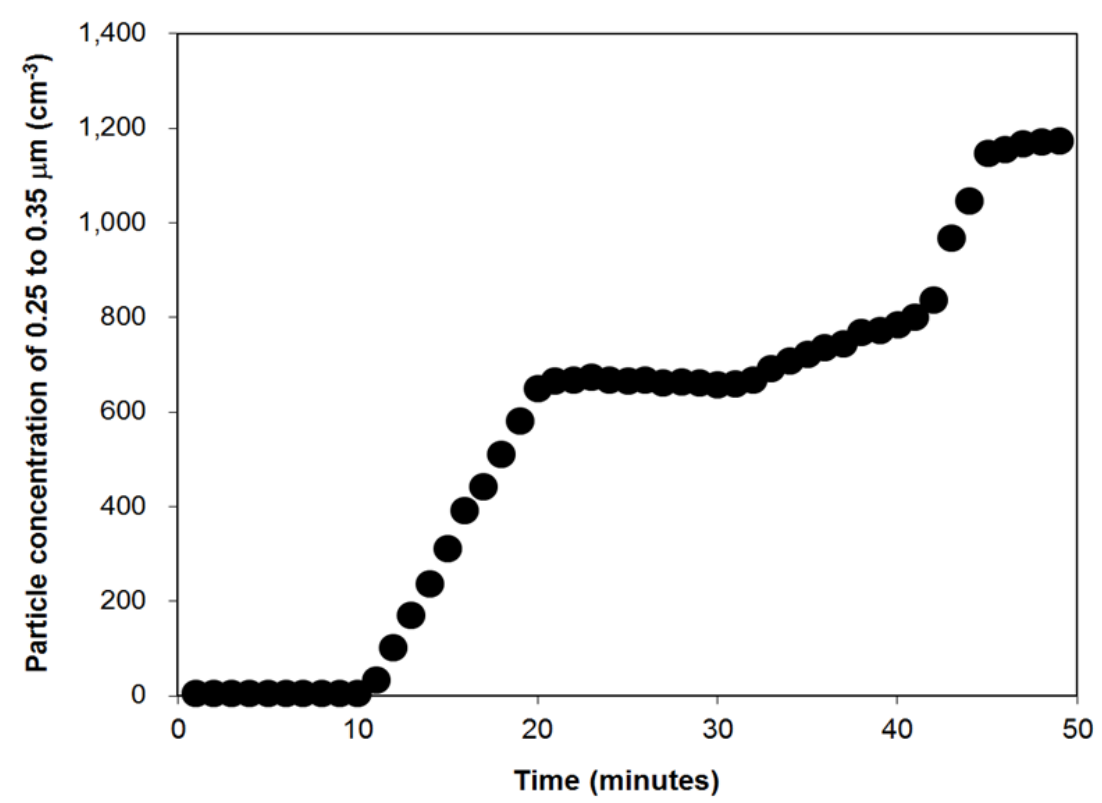

Fig. 6. Changes in the levels of particles $0.25-0.35 \mu \mathrm{m}$ in size after operation of the humidifier.

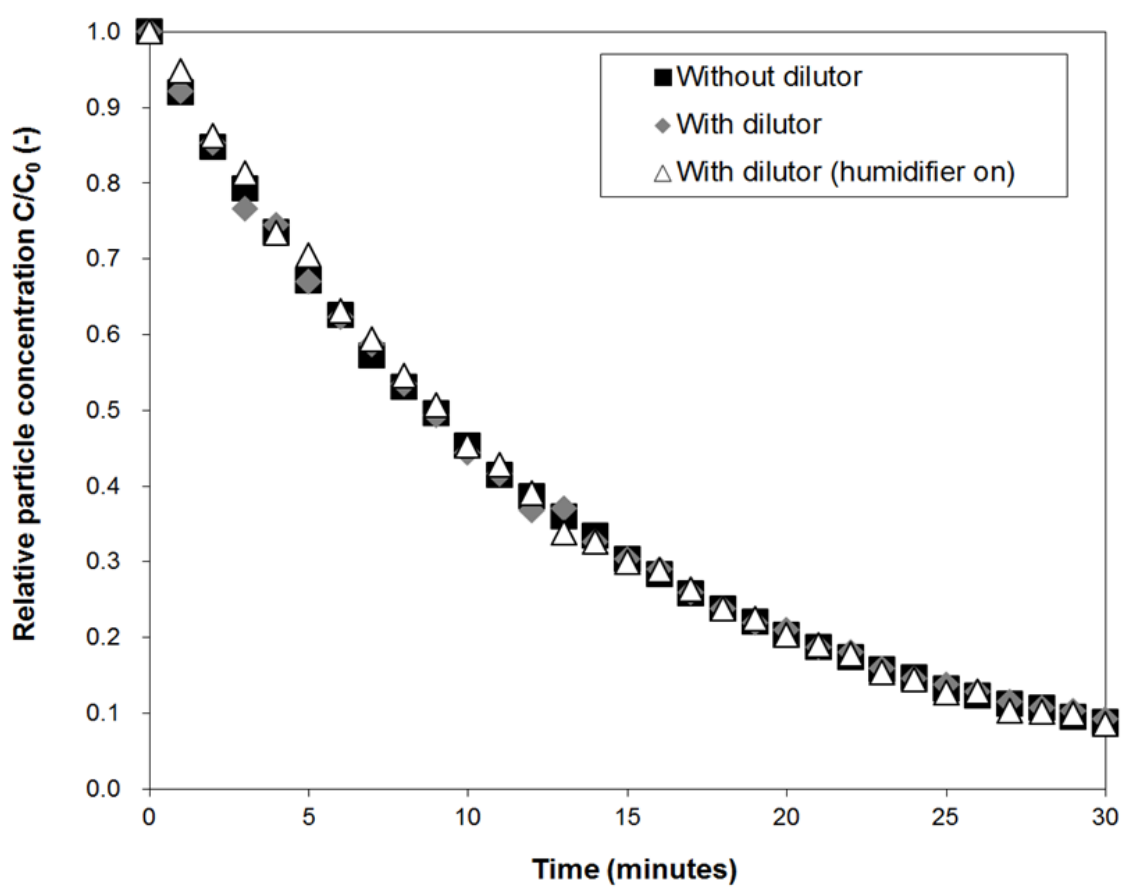

Fig. 7. Relative concentrations of $0.3-\mu \mathrm{m}$-diameter $\mathrm{KCl}$ particles over time after air cleaner operation under different dilution conditions.

chamber under various sampling conditions. The air purifier was operated in the low flow rate mode after injection of $\mathrm{KCl}$ particles. Sampling was performed with and without the dilutor, as dictated by the Korean air purifier test standard (SPS-KACA002-132). Then, dilutor sampling was performed once more during humidifier operation. The clean air delivery rate (CADR) of the air purifier can be calculated by multiplying $30 \mathrm{~m}^{3}$ (the test chamber volume) by the decay constant $\mathrm{k}$ in the following equation: $\mathrm{C} / \mathrm{C}_{0}=\exp (-\mathrm{kt})$. For the "without dilutor" condition, the
CADR was $2.43 \mathrm{~m}^{3} \mathrm{~min}^{-1}$. For the "with dilutor" and "with dilutor during humidifier-on" conditions, the values ranged 2.40-2.43 $\mathrm{m}^{3} \mathrm{~min}^{-1}$. Thus, even if condensed water droplets are present, solid particles can be precisely measured by drying condensable particles in our new dilutor.

\section{CONCLUSIONS}

We developed a porous-tube dilutor featuring two-stage (hot and cold) dilution that suppresses and removes 
condensable particles. Diesel engine exhaust particles exhibited a bi-modal size distribution: a nuclei mode for condensable particles and an accumulation mode for solid particles. By increasing the flow rate of the first-dilution hot air into the porous tube dilutor, the condensable nucleus was suppressed, and the accumulated solid particles were thus selectively measured. The accumulated solid particles in coal-fired boiler exhaust were also selectively measured. The loss rate of particles larger than $3 \mu \mathrm{m}$ in diameter was lower than that of the ejector method (the DEED). To separate and measure solid particles in a $30-\mathrm{m}^{3}$ test chamber when they were mixed with water particles generated by a humidifier, our new dilutor eliminated the latter particles via drying.

\section{ACKNOWLEDGMENTS}

This work was supported by the Korea Institute of Energy Technology Evaluation and Planning (KETEP) and the Ministry of Trade, Industry, \& Energy (MOTIE) of the Republic of Korea (Grant No. 20161110100140).

\section{REFERENCES}

Burtscher, H. (2005). Physical characterization of particulate emissions from diesel engines: A review. $J$. Aerosol Sci. 36: 896-932.

Deuerling, C.F., Maguhn, J. Nordsieck, H.O., Warnecke, R. and Zimmermann, R. (2010). Measurement system for characterization of gas and particle phase of high temperature combustion aerosols. Aerosol Sci. Technol. 44: 1-9.

Environmental Protection Agency (1998). Stationary source control techniques document for fine particulate matter.

Health Effects Institute (2017). State of global air 2017. Special Report. Boston, USA.

Li, X., Wang, S. Duan, L., Hao, J. and Long, Z (2011). Design of a compact dilution sampler for stationary combustion sources. J. Air Waste Manage. Assoc. 61: 1124-1130.

Lipsky, E.M. and Robinson, A.L. (2005). Design and evaluation of a portable dilution sampling system for measuring fine particle emissions. Aerosol Sci. Technol. 39: 542-553.

Lipsky, E., Stainer, C.O., Pandis, S.N. and Robinson, A.L. (2002). Effects of sampling conditions on the size distribution of fine particulate matter emitted from a pilot-scale pulverized-coal combustor. Energy Fuels 16: 302-310.

Lyyränen, J. Jokinielmi, J., Kauppinen, E.I., Backman, U. and Vesala, H. (2004). Comparison of different dilution methods for measuring diesel particle emissions. Aerosol Sci. Technol. 38: 12-23.

Received for review, August 29, 2018

Revised, August 29, 2018

Accepted, October 8, 2018 